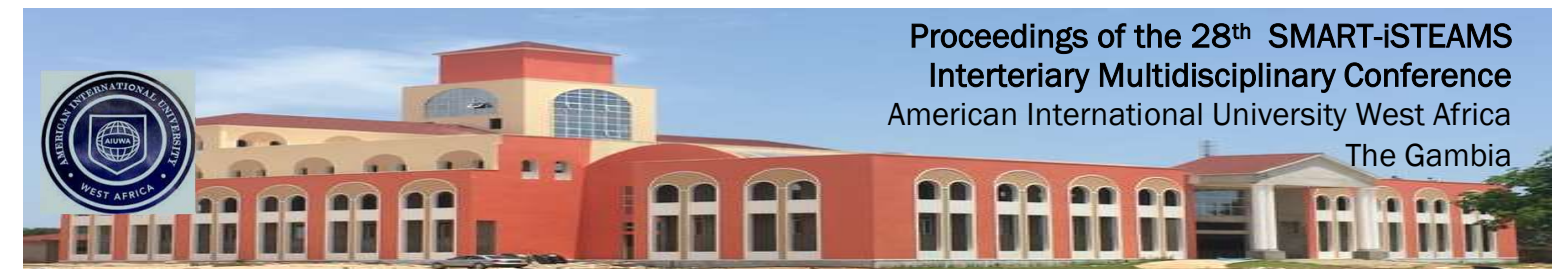

Full Research Paper

\title{
User Centered Design Approach and Built Environment Sustainability
}

\begin{abstract}
1Abatan, Isreal Oluseyi 2Abatan Taiwo Titus,

1Department of Architecture, 2Department of Electrical and Electronics Engineering Bells University of Technology Ota, Ogun state, Nigeria
\end{abstract}

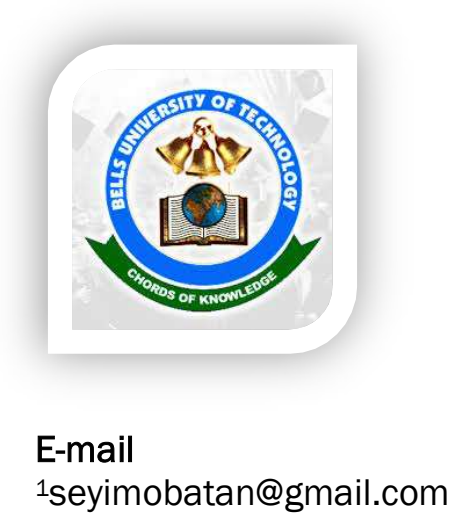

Phone:

$+2347085666612$

\begin{abstract}
In the past few decades, issues pertaining to Built Environment Sustainability (BES) has attracted much attention in form of scholarly debates and researches. User Centered Design Approach (UCD) has become one amongst many other approaches or strategies being advocated by researchers to ensure built environment sustainability. This is because, firstly, researches have established the users as central in the planning, design, construction and management of any built environment. Secondly, from the stand point of the users, performance evaluation of built spaces are conducted, of which the outcomes have always shown the actual to be far from the expected in meeting the needs and expectations of would-be-users. This is probably attributed to outright exclusion and/or "poor understanding" of the users by the Architect or Designer and other parties involved in the design and construction processes. The paper attempts an explorative study of the dynamic role and place of users, usefulness and usability concepts within the built environment. The paper emphasised on the need for more user engagement in the design process and addresses the challenges and opportunities of a User Centered Design (UCD) approach towards attaining Built Environment Sustainability (BES).
\end{abstract}

Keywords: User centered design, Performance Evaluation, Built environment sustainability, User engagement.

Proceedings Reference Format

Abatan, I.O. \& Abatan, T.T. (2021): User Centered Design Approach And Built Environment Sustainability. Proceedings of the 28th iSTEAMS Intertertiary Multidisciplinary Conference. American International University West Africa, The Gambia. October, 2021. Pp 57-66 www.isteams.net/gambia2021. DOI - https://doi.org/ 10.22624/AIMS/iSTEAMS-2021/V28P5 


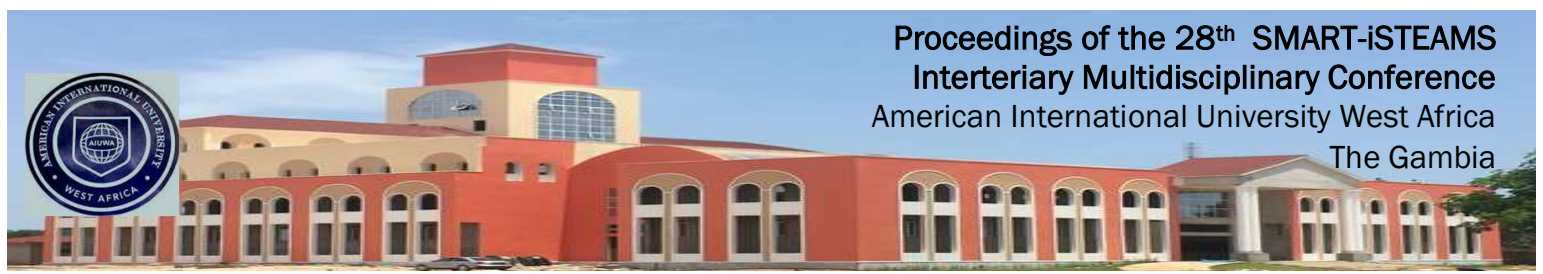

\section{INTRODUCTION}

User Centred Design tries to optimize the fit of product and services with how users can,want and need to use them, rather than forcing the users to change their behavior to accommodate the product and services Chun,et al (2015). This approach to designing and constructing the built environment is referred to in many ways by many scholars as; respect for users, user centered, user sympathetic, user tailored, user based, user oriented, people centered (Agerfalk, 2001; Rigolon, 2005). To many built environment scholars and researchers, assessing built environment through the user's experience is premised on the fact that it is unlikely that environment can be found that have been built not to accommodate human activities and for a purpose not relate to human use (Vischer, 2008).

A study conducted by Ibem et al (2013) established that for a building to perform its primary purpose of providing occupants with conducive, safe, comfortable, healthy and secured indoor environment in order to carry out different activities ranging from work, study, leisure and family life and other social interactions, such buildings must have been designed, planned, constructed and managed based on standards and specifications established by government and professionals who are supposed to have adequate knowledge of users' needs and expectations. Further studies have however shown that many times, these standards and specifications do not conform to changing needs and expectations of users and the users are not always satisfied with the performances of their buildings (Meir et al (2009); Kian et al, 2005; Kim et al, 2005).

Kar et al (2017) put it clearly the reason why many a times buildings do not serve their intended purposes is because their designers often make assumption-based decisions about needs of people and their kind of built environment that can satisfy them without any arduous scientific decision making process. And that the whole process from conception to completion often run independent of direct user involvement. Such emerging built environments as shown in the figure 1, are faced with problems of increasing loss of functionality, vandalism, lack of attachment, desire for remodeling or modifications and conversions or outright abandonment of completed buildings. Ibem et al (2013) added that consequences of such built spaces are manifested in form of building related illness and "sick building syndrome".

It is important for Architects and other built environment professionals who design, construct and maintain buildings to have adequate knowledge of users' needs and preferences and properly integrate the users' perspectives into the building design in order to generate a sense of belonging and attachment and positive attitude of the users to spaces and places created for their uses.

In Nigeria, there is inadequate research efforts in this area of study and physical evidences abound of schemes that were implemented at the various tiers of government that have shown the lack of understanding and adequate knowledge of users and how buildings could meet their needs and expectations. Most times, the active users are not even brought into the picture whereas Kar et al (2017) established that the field test for any design is when the users come into the picture. 


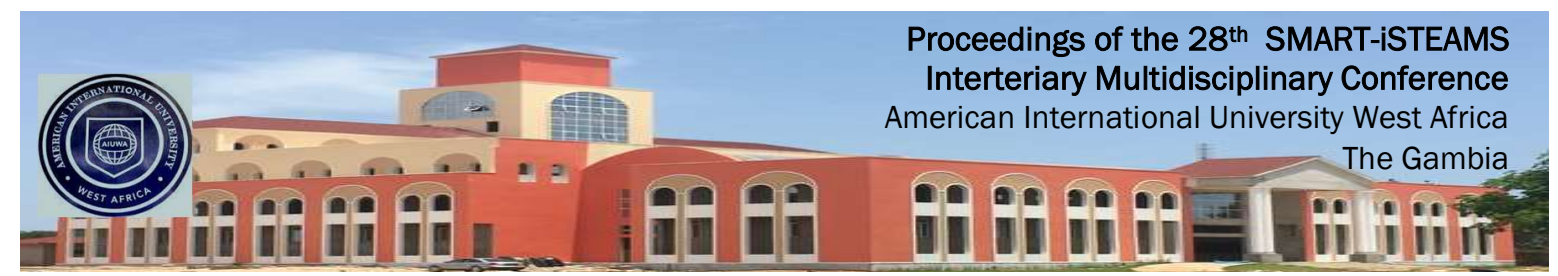

According to Sani et al (2011), even in both primitive and traditional societies, the user was directly involved in design and construction process of his dwelling. In order to avoid the consequences of this built environment sustainability challenges, more knowledge and understanding of the roles and responsibility of the would-be-users is necessary and a positive shift towards more user engagement or participation.

It is against this background that this study using the search and review of literature approach, attempts an exploration of the dynamic roles of the end users, usefulness and usability of places within the built space. It further emphasized on the need for more user engagements in the architectural design process, and addressed the challenges and opportunities of a user centered design approach towards attaining built environment sustainability.

\section{USER AND USER CENTEREDNESS}

Who is the user? The international organization for standardization ISO 6241-1984(E) defined user as "person, animal or object which a building is designed to accommodate". User centeredness in the built environment is an approach that based the performance or behaviour related to the use of a building on user requirements (ISO 6241-1984(E) which is a statement of needs to be fulfilled by a building. This approach widely describes and establishes the user as occupying a central role in the built environment evaluation process. User centered design tries to optimize the fit of product and services with how users can, want and need to use them rather than forcing the users to change their behaviour to accommodate the product and services (Chon et al, 2015). This approach was first defined by Norman (1988) as "a philosophy based on the needs and interests of the user, with an emphasis on making products usable and understandable.

Chin et al (2015) established that Eason (1995) itemized two possible meaning of user centeredness, "Design for User" and "Design by Users". The first calls on the designer to gather information about human behaviour and design the product and services for users, while the second incorporates the user more substantively within the design process as shown in the conceptual framework diagrams. The term is widely used in software design, graphical design and in healthcare products used in the hospitals and in design and construction of the built environment (Chon et al, 2015).

\section{THE BUILT ENVIRONMENT}

According to Bittencourt, et al (2015), the built environment refers to the building or public space, covered or uncovered environments, organized and animated, constituted a kind of aesthetic and physical, psychological and informative, designed to please, serve, protect and unite the people in the exercise of its activities. Dimuna (2011), used the physical environment and built environment interchangeably. He referred to the built environment as the buildings and spaces between them. The physical environment is considered as the most important component of the environment because it is that aspect with which the organism, individual, community or population is in direct contact and whose effects are mostly directly visible and tangible. 


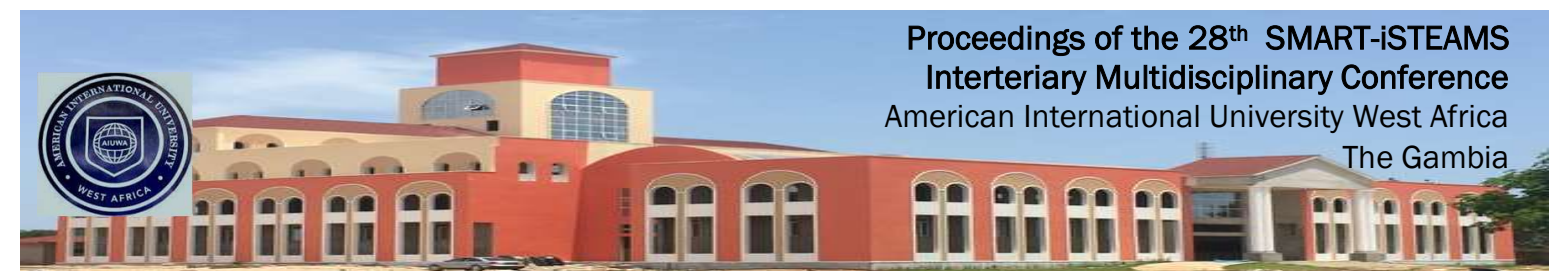

\section{THEORETICAL FRAMEWORK}

Two opposite existing user centred theories on the built environment have since being developed and deeply rooted in the user centred approach. One is environmental determinism while the other is social constructivism. Both theories explain the influences behind human behaviour that drive the user's experience within the built space.

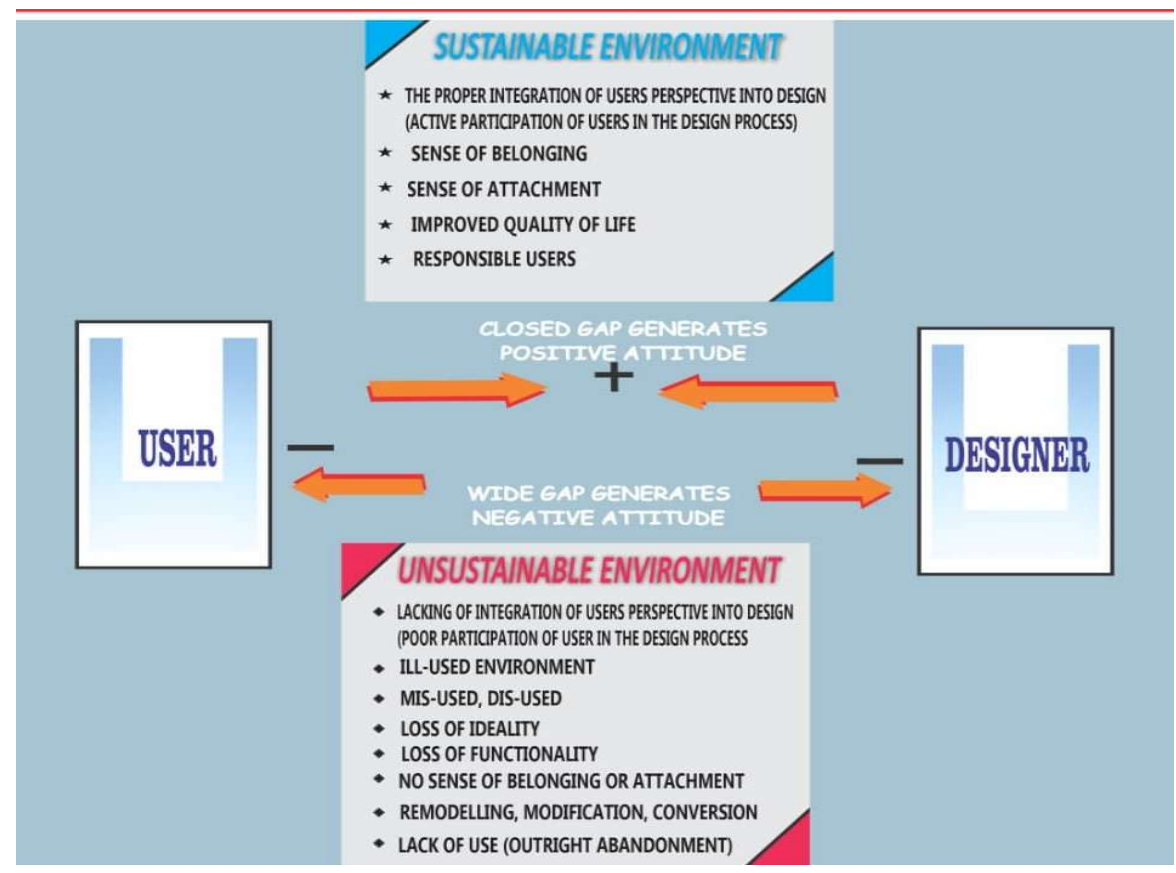

Fig. 1. Diagram of Conceptual Framework of Interaction between Designer and End-User

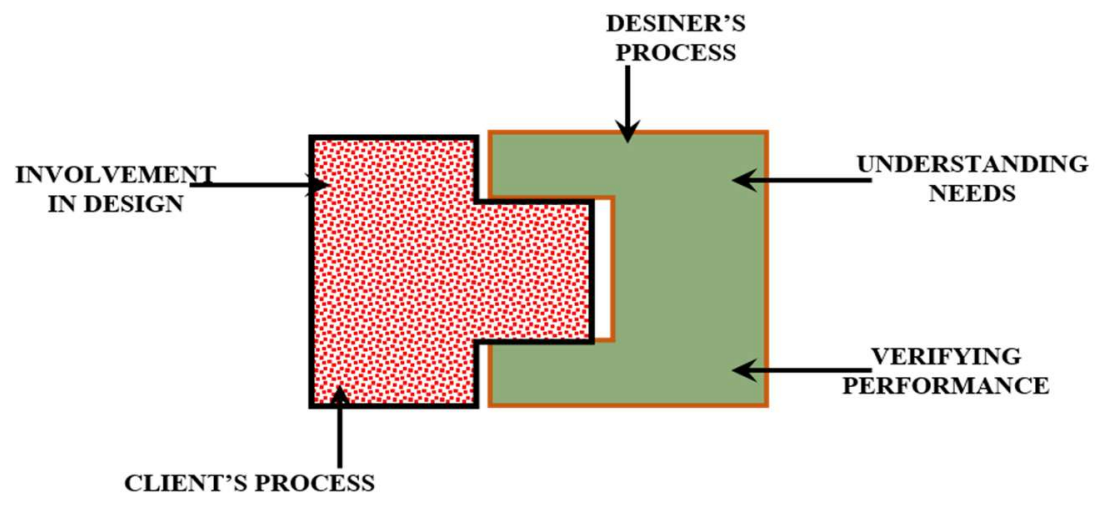

Fig. 2. The Intertwining Relationship Between the Client and the Design Team 

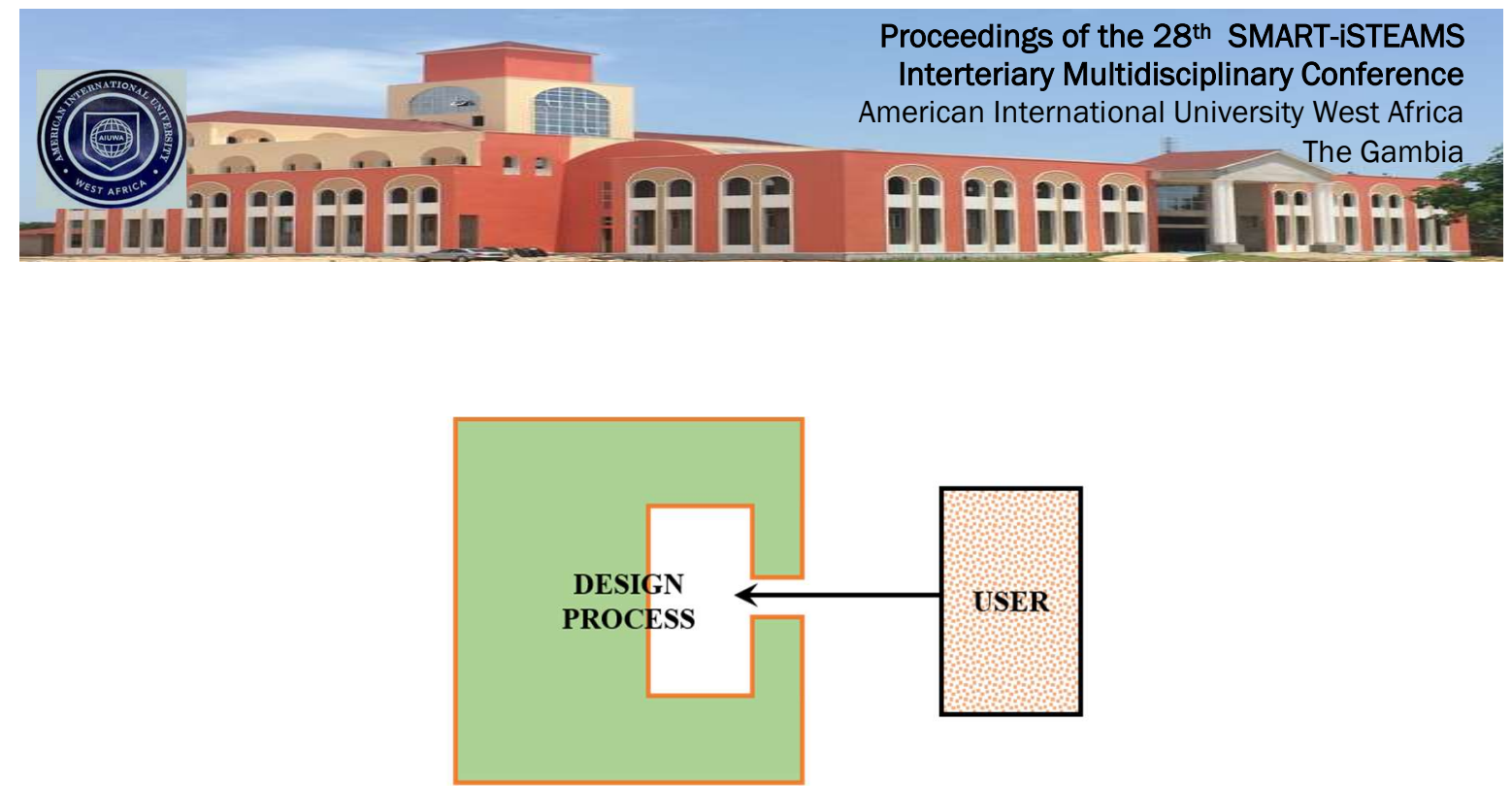

Fig. 3. Bringing User into Design Process of Building

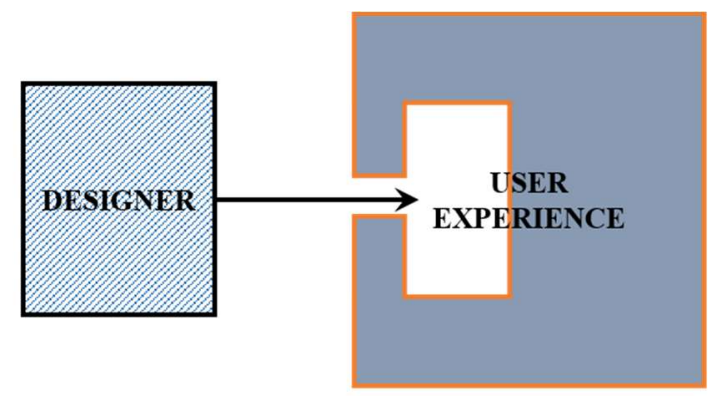

Fig. 4 Bringing Designer into User Experience of Building

\subsection{Environmental Determinism}

As outlined by Vischer (2008), the environment deterministic perspective views users behaviour as a result of the environment, that is what is built, and the environment thereby created causes users to behave in certain ways, many of which are predictable. This approach tended to be favored by members of the design professions who see its immediate applicability to practice. A significant amount of research in environmental psychology is based on the environmental determinism approach, where efforts are made to identify how human behavior is influenced by features of the spaces people occupy.

The environmental determinism approach is today furthered in the form of user satisfaction as an outcome measure. According to Vischer (2008), using the stimulus-response logic of experimental psychology, this approach posits that user satisfaction is a meaningful and measurable behavioural response to features of the physical environment. Vischer (1985), earlier argued that little efforts have been extended to understand exactly what users are reporting when they rate themselves satisfied (or not) with the built space they occupy, nor the influences of other non-space factors on the "satisfaction" that is being reported. 


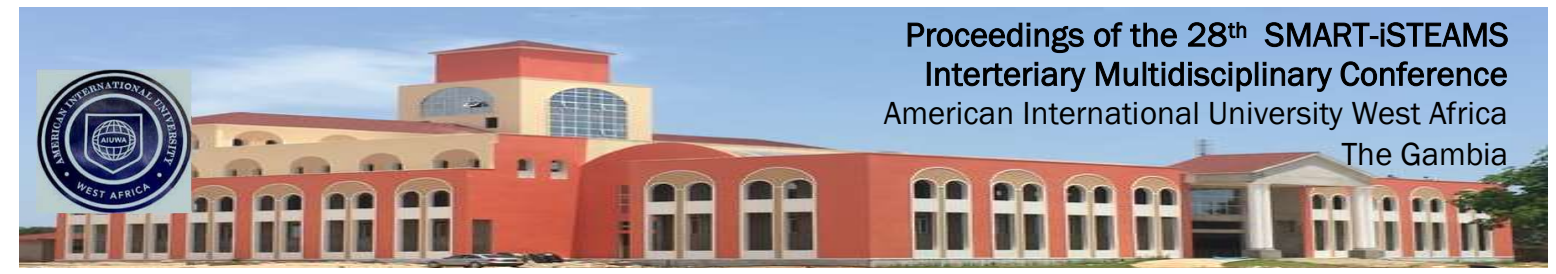

\subsection{Social Constructivism}

This premised that human experience and therefore reality is entirely socially constructed and exists as a function of social and biological influences (Mead, 1962). Watson et al (2014) stated that this approach emphasizes the importance of social context over the built environment in explaining behavior. Watson et al (2014) further argued that the relationship between building design and building users does not occur in a social vacuum, yet design quality evaluation rarely considers social context as a mediating factor in the relationship between buildings and building users has been notably absent from the majority of the research literature.

Social constructivism believes that behavior results from learned social norms and patterns and is not influenced by the physical environmental context in which it occurs. If the physical environment has any role to play, it is at a symbolic level and as a mediator of the social relationship that determine behavioral outcomes (Blomer, 1969). The theory is clear in its position that in a given situation, building users' behaviour is influenced not just by the space they occupy but by their feelings, intentions, attitudes and expectations as well as by the social context in which they are participating.

\section{USEFULNESS AND USABILITY OF BUILT SPACES}

Usability in Architecture is a relatively new concept, often understood to be the functionality or the building's ability to carry out the tasks envisaged for it, to its efficiency, practical utility or value to the user, considering the financial resources available. Usability and usefulness are complimentary (Alenxander, 2006). Usefulness is defined as "the quality or fact of being useful". That is "capable of being put to use for an end or purpose". The usefulness of a built space is determined by the value or importance it has, particularly in terms of its utility. The usefulness of a built space is the extent to which the needs to be fulfilled by it as expressed by the user requirements/user needs is fulfilled or achieved.

Usefulness is about creating spaces and scales to meet user requirements and how they relate to spaces (Bittercourt, et al 2015). For effective understanding of usability of the built environment, the situational and contextual user experience is important as much as some other factors such as cultural, aesthetic, symbolic, technological, ergonomic etc. According to Alexander (2006), usability means "getting closer to the user" and focusing on user perceptions of the ease and efficiency with which they can use a space or facility. Inspite of the fact that within the framework of architecture and built environment literature, the concept of usability is not unknown, there is little researches involving usability in Architecture and much efforts are still required to improve knowledge in this area towards improving the users experience within the built environment. 


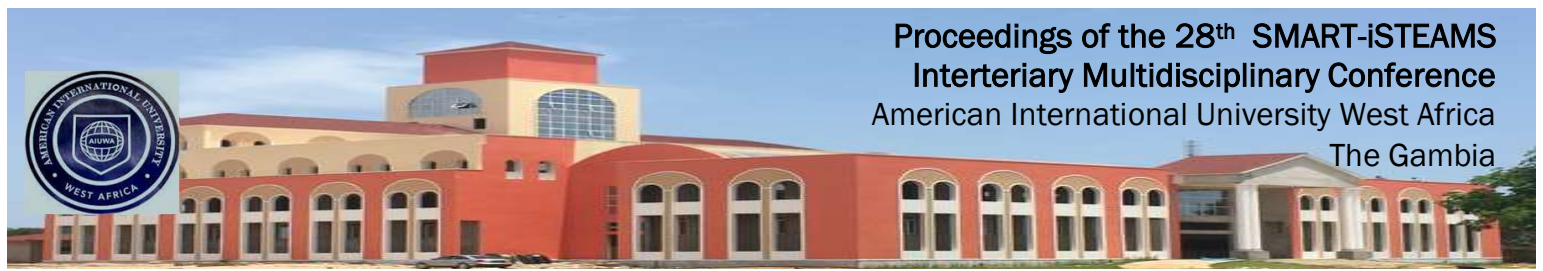

\section{USER ENGAGEMENT IN THE DESIGN PROCESS}

User engagement, user participation, user collaboration, user involvement refers to all the same thing (Sani, et al, 2002). That is the process of incorporating users into the designing or redesigning of their environments/buildings. Their experiences and practices are incorporated and use to inform design activities. User engagement in the built environment is undeniably important to achieving a built environment sustainability. Agerfalk (2001) established from time immemorial, built environment professionals have always engaged with would-be-users whether at the level of briefing, planning, designing, stakeholders management etc.

However, in the developing countries, user engagement practices and processes has not been deepened and has assumed a dimension of less importance especially in low or middle income schemes. This probably may be done to the social/economic status of the would-be-users that is generally low especially in the face of the challenges to ensure the quality of the environment. Participation enables people to work together in a spirit of collaboration and to make decisions about their own lives, Sani et al, 2011. More importantly, participation enables the democratization and the active involvement of all stakeholders in the design decision process. This enables users to participate in everything that influences them with regards to their environment. Participation further plays an important role in empowering community members to become part of the general political process and to have a voice in decisions that shape their community. Nowadays, the introduction and development of virtual technology has changed the dimensions of user engagement as reactions and remarks about the proposed design solution can be assessed in form of 3Ds, 4Ds etc.

User engagement makes the direct user an active participant in the design decision process. According to Sani, et al (2011), researchers see participation not just as a means to involve users more efficiently in the production of space, but also a means to redirect architectural culture. Also as means for tapping cultural pluralism, which in turn, has been considered to be a potential for achieving diversity of form in architecture (Albrecht, 1988).

Mostly, through participation, a highly successful and integrated design is achievable. This success is usually attributed to the understanding of users' needs and preferences. Participation boosts the feeling of self-confidence of users and improves sustainability as seen in Fig. 1 of the conceptual framework. This is because the user understands the design and participates in setting proper solutions which is acceptable to all. Also, increasing user engagement or participation serves as an effective tool for avoiding social exclusion.

\section{TYPES OF USER ENGAGEMENT}

User engagement may be of two types. Namely, active and passive engagements.

Active engagement is where an active user emerges in a case where the Architect/designer deals with an individual client, collects, interprets and designs brief and design a "one of a kind" building tailored to meet individual and family needs and aspirations. Here, the level of user participation is high and helps towards the creation of responsible users who can make decisions on "their" place. Passive engagement on the other hand, according to (Madge, 1968) is a case where the designer/architect has two clients: one who pays for what is built and another who use it. 


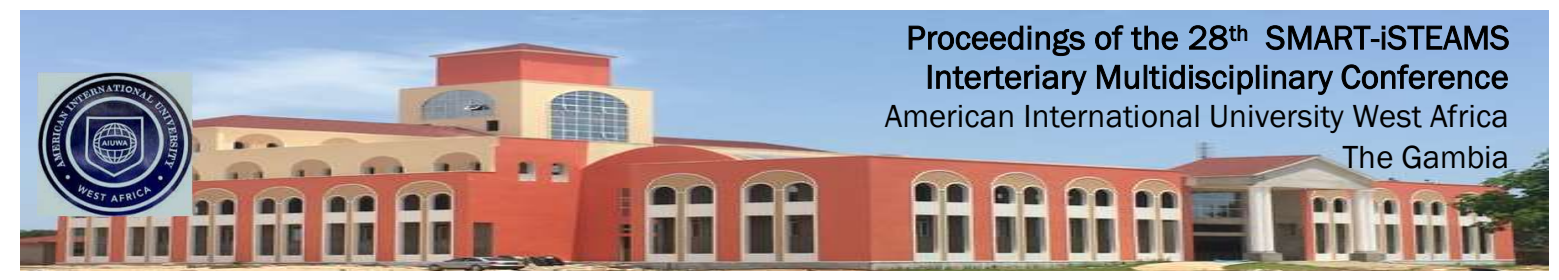

The problem here is, it is usually difficult to plan for the needs of users whose life style is not known nor readily available to plan with (Zeisel, 1986). This situation facilitates the emergence of passive users as a result of the gap between the designer and the direct end-users, who are unwilling to or were never involved in any design decision making process. Sani, et al (2011) asserted that the result of this is total alienation of the user from the setting whether at the scale of personal or communal spaces shared with others. Sometimes, this may lead to impoverishment of the environment due to ill use (vandalization) of lack of use of space (abandonment). This area is open to further research studies particularly in the area of environment-behaviour research. This is usually the case in government schemes particularly in developing countries like Nigeira i.e. Kanji resettlement scheme.

\section{LEVELS OF USER PARTICIPATION}

Next we discuss the levels of user participation

1. Zero participation: here, the designer is the main controller of the project. This is usually the case when the paying client is a government authority such as municipalities and government ministries.

2. Low Level participation: user participation is small and insignificant. The Architect remains the controller on the project.

3. Equally balanced level user participation: here, the opinion of the user is equal to the opinion of the Architect. They work together to produce a project which is expressive of the culture of the users and community and the architect's style.

4. The high level user participation: here, the first controller is the user. The Architect only guides and advises. The user group has the means (cultural and economic) to demand for the architect he/she desires. Examples of such scheme are Shrines, temples and so on.

\section{BENEFITS OF A USER CENTERED DESIGN APPROACH}

The benefits of user centered design approach include:

1. Social Responsibility and Sense of Belonging: According to Rigolon (2011), including the people in the design process is not only a form of social responsibility but also a way to increase the people's sense of ownership towards the designed spaces.

2. Improved Users' Experience: Many researchers have indicated that there is an improved users' experience especially when users have the opportunity to regulate their environment. Kalvelage, K.J. et al (2014); Vischer, J.C. (1985 \& 2008).

3. Data Collection, Analysis and Integration: Researchers have pointed the importance of right timing for the collection and integration of data from users in the design process. This approach is being explored extensively in the area of product design of consumer goods and researchers have advocated for the application of this strategy in the built environment too. Information coming from users should be part of the design process as early as possible. As such, the interaction should start from the earlier stage such that users would not come late and be seen as factor of delay or cost rise or an outright obstacle since design is almost completed. Data collected must be able to accommodate the people's direct experience possibly from general early childhood experience and users' diversity. Every society shows a series of standards and 


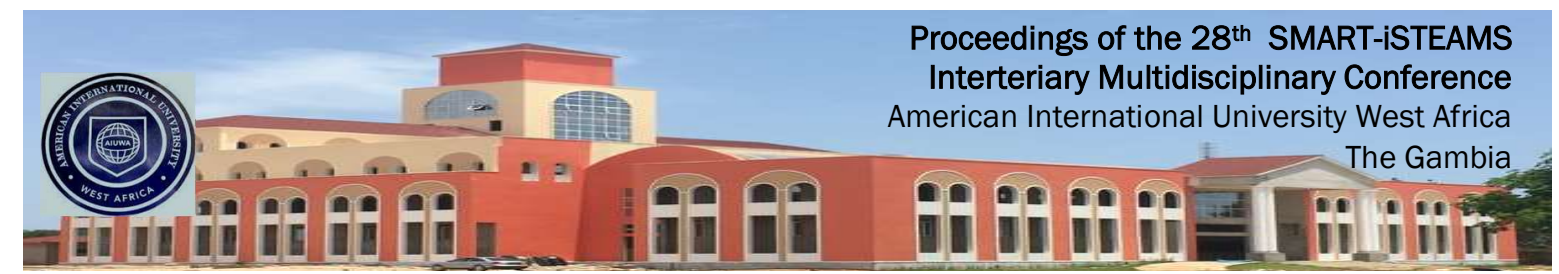

conventions about their expected lifestyle. This will generally improve the usability and appropriateness of designed built environments.

4. Well Developed Techniques/Strategies: The generation, collection, analysis and integration of user derived data is a function of the development of appropriate techniques, methods or strategies. Data can be collected through interviews, questionnaires, briefing, workshops etc., without unnecessarily increasing the process duration.

5. Future Data Bank: Data generated from the interaction of Architect with users will serve as a veritable data bank and a useful source of knowledge for future purposes for the Architect.

6. Improved Sustainability of the built environment: Fig. 1 of the conceptual framework shows the results of the interaction that occurs between the designer and users in the design process. The result of close interaction closes the gap while little or no interaction widens the sustainability gap. Proper integration of users perspectives into the design process is highly beneficial and could be a way to correct some of the ills in our built environment spaces.

\section{CHALLENGES OF USER CENTERED DESIGN APPROACH}

In this section we identify the challenges of user-centred designs

1. 1.Loss of Autonomy: Architects/Designers are limited as they do not have the "last word" about design/conceptual generation. He must particularly "renounce" his creative power to accept users' considerations. The complexity of the task makes design a multidiscipline and interdisciplinary team work. Designers are forced to interact with other professionals and with users as well. Architects are made to "listen" to the dictates of the people in terms of how they like their spaces to be.

2. Government Policy: Rather than decisions about what, where and when to build been based on and driven by users, it is usually based on government policy which can be construction processes and technology, building codes, standards, specifications etc.

3. True Representation: In user centered design approach, true representation is key in terms of ensuring that the experience and opinions of the representative users who are engaged with is truly representative of those of the whole of user group (Chon et al, 2015).

4. User Behaviour: A user centered design approach may not necessarily guarantee a sustainable user behaviour despite the fact that there is potential for designers to influence user behaviour in a more sustainable direction. This depends on the tools and methods employed to realize these potentials.

\section{CONCLUSION}

Built environment researchers have shown that making design and construction decisions based on the needs, preferences, perception and values of the inhabitant's users can create user-responsive and sustainable built environment (Vischer, 2008; Kar et al, 2017). To achieve better buildings how users interact with their built-environment must be understood. 


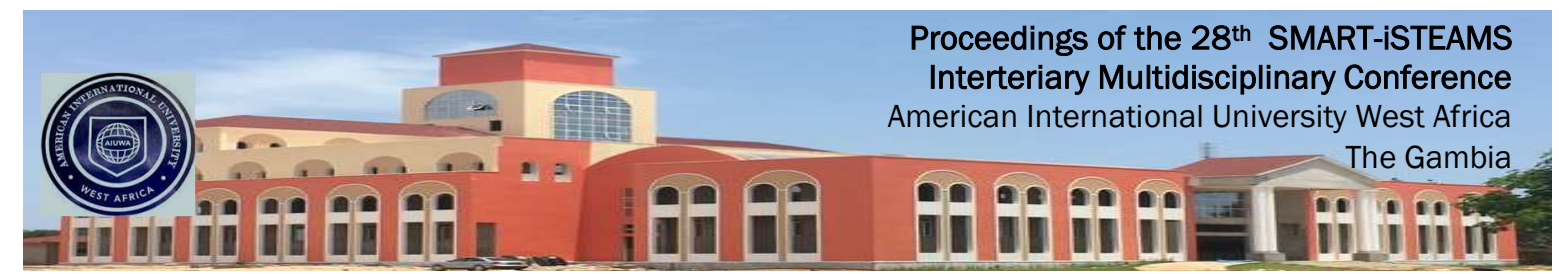

\section{REFERENCES}

1. Agerfalk, P.J. (2001). “Who's the user in user centered design? 102-104.

2. Albrecht, J. (1988). Towards a theory of participation in Architecture: An examination of Humanistic planning theories. Journal of Architectural Education, 42(1), pp 24-31.

3. Alexander, K. (2006). The application of usability concepts in the built environment. Journal of facilities management vol.4, No.4, 2006. Pp 262-270.

4. Bittencourt, M.C., Pereira V.L. \& Junior W.B. (2015). The usability of architectural spaces: objective and subjective qualities of built environment as multidisciplinary construction. $6^{\text {th }}$ International conference on Applied human factor and ergonomics (AHFE 2015) and the Affiliated conference, AHFE 2015.

5. Chun. M.H., Harty, C. and Schweber, L. (2015). Comparative study of user centered design approaches. Proceedings on 31 ${ }^{\text {st }}$ Annual ARCOM Conference, 7-9 September 2015, Lincohn, UK, Association of Researchers in Construction Management, 1125-1134.

6. Dimuna, O. (2011). The social effects of the built environment: A case study of selected Buildings in Benin City, Nigeria. Journal of Human ecology, vol.34, issue 3: pg 189-196, 2011.

7. Eason, K.D. (1995). User-centered design: for users or by users? "Ergonomics" vol. 38, No. 8, 1667-1673.

8. ISO 624 (1984). Performance standards in building- Principles for their preparation and factors to be considered. $1^{\text {st }}$ edition 1984-05-01.

9. ISO, 1998, ISO 9241-11 Ergonomic requirements for office work with visual display terminals (VDTs)- Part II: Guidance on usability Generation. Suitzerland: International Organization for Standardization.

10. Jordan, P. (2002). An introduction to usability. Philadelphia: Taylor \& Francis Group, 2002.

11. Kalvelage, K.J. and Dorneich, M.C. (2014). A User-Centered Approach to User-Building Interactions. Industrial and Manufacturing Systems Engineering Conference Proceedings and Posters, lowa State University Digital Repository. digirep@iastate.edu.

12. Kar, A.Z., Sarkar, A (2017). Exploring the role of environment-behavior studies (EBS) in residential Architecture-From Literature Review to field study. International Research Journal of Engineering and Technology (IRJET) vol. o4, issue 11, Nov, 2017.

13. Luck, R. (2003). Dialogue in participatory design. Design Studies. Vol. 24, No:6, pp 523-535.

14. Meir, I.A., Garb, Y., Jiao, D., Gcelsky, A (2009). Post occupancy evaluation: an inevitable step toward sustainability. Advances in building energy research 3, 189-220

15. Munter, A. (2011). Usability and User driven innovation, unity or clash? Paper delivered at $13^{\text {th }}$ International FM2REM-Congress, Kufstein, January 19-21, 2011.

16. Nielsen, J., 2009. What is usability? In W. Chausney- User Experienced Re-Mastered. Your guide to getting right decision. San Francisco: Morgan Kaufman, 2009, pg 3-22.

17. Norman, D. (1988) "The design of everyday things", New York, Basic books.

18. Rigolon, A. (2005)- People Centered Architecture. Numero 2- giugno 2011 https://www.researchgate.net/publication/286459792.

19. Sanoff, H. (2000). Community Participation Methods in Design and Planning. NY John Wiley.

20. Vischer, J.C. (1985). The adaptation and control model of user needs: a new direction for housing research. Journal of Environmental psychology, 5(3), 287-298.

21. Vischer, J.C. (2008). Towards a user-centered theory of the built environment. Building research information (2008) 36 (3), 231-240.

22. Watson, K.J., Evans, J., Karronen, A. and Whitley, T (2014). Re-conceiving building design quality: A review of building users in their social context. Indoor and built environment, 2016, vol. 25(3), 509-523.

23. Wikipedia, https://en.wikipedia.org/wiki (built environment) 